\title{
Molecular Analysis of Nipple Fluid for Breast Cancer Screening
}

\author{
Karijn P.M. Suijkerbuijk ${ }^{\mathrm{a}}$ Elsken van der Wall ${ }^{\mathrm{b}}$ Marc Vooijs $^{\mathrm{a}} \quad$ Paul J. van Diest $^{\mathrm{a}}$ \\ a Department of Pathology and bivision of Internal Medicine and Dermatology, University Medical Center Utrecht, \\ Utrecht, The Netherlands
}

\section{Key Words}

Nipple aspiration $\cdot$ Breast cancer $\cdot$ Early detection

\begin{abstract}
Lack of sensitivity and specificity of image-based breast cancer screening has urged the exploration of alternate screening modalities. Nipple fluid, which contains breast epithelial cells, is produced in small amounts in the breast ducts of nonlactating women and can be collected by noninvasive vacuum aspiration. After administration of nasal oxytocin, nipple aspiration yields sufficient material for molecular analysis in the large majority of women. Whereas nipple fluid cytology appears to have only a moderate correlation with breast cancer development, methylation holds promise as a more appropriate biomarker, since methylation aberrations occur as an early and frequent event during carcinogenesis. Using quantitative multiplex methylation-specific PCR, methylation can be detected in minute amounts of DNA extracted from nipple aspirates, precluding the need for more invasive intraductal approaches such as ductal lavage and random periareolar fine needle aspiration. The application of genomic and proteomic diagnostics to nipple aspirates therefore provides unprecedented opportunities for early breast cancer diagnosis amendable to populationbased screening.

Copyright $\odot 2008$ S. Karger AG, Basel
\end{abstract}

\section{Introduction}

Breast cancer is the leading cause of cancer death in women in the Western world. In the last decades, clinical and radiological screening have been proven to reduce breast cancer mortality [1], with recent improvements such as magnetic resonance imaging and digital mammography potentially further increasing the accuracy of radiological detection. Despite these advances, current screening modalities miss 1 of 4 breast tumors [2] in high-risk women, indicating that new breast cancer screening tools are urgently needed. A new screening modality could very well be found in the analysis of nipple fluid that is produced in small amounts in the breast ducts of nonlactating women. Nipple fluid contains breast epithelial cells, free DNA and proteins, and can be collected in a noninvasive manner by vacuum aspiration. We and others have shown that in nipple fluid relevant (epi)genomic changes can be detected, either from cells shed from lesions or from neighboring cells suffering from a field defect (see below). Therefore, nipple fluid could become a valuable source for population-based screening of high-risk women, signaling (epi)genetic changes before breast cancer is radiologically or clinically detectable.

\section{KARGER}

Fax +4161306 1234

E-Mail karger@karger.ch

www.karger.com
Karijn P.M. Suijkerbuijk, MD

Department of Pathology

University Medical Center Utrecht

NL-3584 CX Utrecht (The Netherlands)

Tel. +31 887556 565, Fax +31 302544 990, E-Mail K.Suijkerbuijk@umcutrecht.nl 


\section{Oxytocin-Supported Nipple Aspiration}

A noninvasive manner to obtain nipple fluid with minimal patient discomfort is by vacuum aspiration. Initially, successful nipple fluid aspiration was reported in only $39-66 \%$ of women $[3,4]$, clearly limiting its potential. Recently, we showed that after administration of oxytocin, nipple fluid suitable for molecular analysis could be obtained from $94 \%$ of participating women [5].

Anesthetic cream (EMLA) is applied onto the nipple and stays on while the breasts are warmed up for $10 \mathrm{~min}$. The subjects are given 1 spray (4 IU) of oxytocin in both nostrils. The nipple is gently wiped with a dekeratinizing agent in order to remove keratin plugs and subsequently cleansed with ethanol. A suction cup (aspirator) is placed over the nipple. Repeated gentle suction by a syringe (10$50 \mathrm{ml}$ ) draws fluid from inside the duct to the nipple surface. Fluid droplets are collected by capillary tubes. The entire procedure is repeated at the other breast.

Oxytocin causes rhythmic contractions of the myoepithelial cells around the acini of the breast, which leads to stimulation and facilitation of the emptying of the glands and is used in the clinical setting to promote nursing. The effect on the breast occurs within $5 \mathrm{~min}$, with a half-life of 3-17 min. Oxytocin-supported nipple aspiration is very well tolerated (fig. 1), with a mean discomfort rating of 1.3 (on a $0-10$ scale) [5].

\section{Ductal Lavage and Random Periareolar Fine Needle Aspiration}

Because of the initial failure to obtain nipple fluid containing sufficient cellular material in part of the population in previous nipple aspiration studies $[6,7]$, alternative intraductal approaches such as ductal lavage and random periareolar fine needle aspiration (RPFNA) have been developed. Compared to nipple aspiration, ductal lavage and RPFNA are more invasive, less cost-effective and cause more discomfort [3].

In the ductal lavage procedure, ducts of the breast are cannulated by a microcatheter, after which a saline solution is infused, followed by aspiration of the fluid. The amount of cells that is obtained through ductal lavage is larger than through nipple aspiration [6], but few to no cellular nipple fluid is obtained by ductal lavage in women that do not yield fluid during classical nipple aspiration $[8,9]$ and problems of recannulating the same duct [8] limit its diagnostic potential.

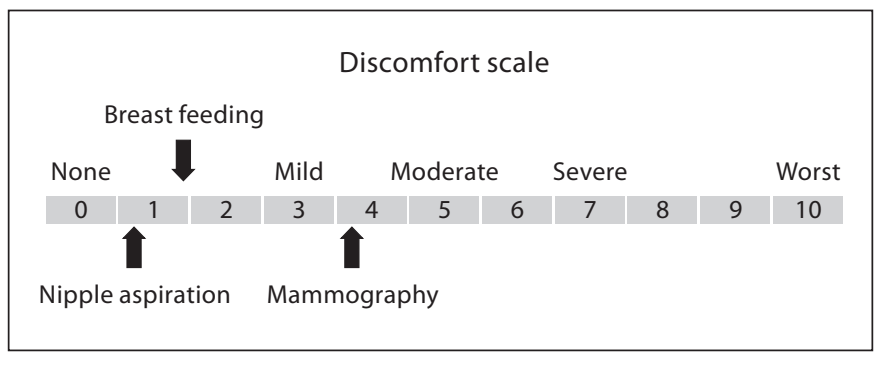

Fig. 1. Discomfort of nipple aspiration in comparison with mammography and breast feeding in a study on female healthy volunteers.

In RPFNA, multiple deep aspirations are performed, targeting different quadrants of the breasts, resulting in sufficient material for analysis in the majority of women [10]. Arun et al. [11] recently reported that the efficiency of RPFNA in producing evaluable specimens for chemoprevention trials in high-risk women is higher than for ductal lavage, making RPFNA a more practical option for breast cancer prevention trials. Still, the invasiveness of the procedures may preclude a role in population-wide screening of high-risk women that requires repeated harvesting of material.

\section{Biomarkers in Nipple Fluid}

Previous studies showed that the presence of atypical cells in nipple aspiration and RPFNA fluid is associated with an increased risk of breast cancer $[7,10]$. However, cytologic atypia appears to have a low reproducibility and the correlation with breast cancer development is not that strong [12], a point of concern being that if a tumor is present in the breast, malignant cells will not always be detectable in the nipple aspirate.

With the development of highly sensitive molecular tools that can detect genomic alterations in only a few cells, methylation analysis might be a more effective biomarker for nipple fluid diagnostics [13]. Methylation plays an important role in the physiology of normal cells as well as in tumor development. In normal cells, it regulates chromatin organization, silencing of transposable elements, $\mathrm{X}$ chromosome inactivation, tissue-specific gene expression and genetic imprinting. In cancer cells, contrarily, hypermethylation of CpG islands occurs [14] in a background of general hypomethylation of the genome [15]. These CpG islands are cytosine- and guaninerich areas in the promoter/enhancer regions of many 
genes that are involved in cell cycle regulation, cell adherence, DNA repair and apoptosis. Hypermethylation of $\mathrm{CpG}$ islands leads to suppression of transcription and thereby inactivation of these genes [14]. It is believed that breast cancer develops by stepwise accumulation of interacting epigenetic and genetic events over time [14]. While the genetic processes are specific events that greatly differ between patients, epigenetic alterations are more generally occurring during breast cancer development [16]. Moreover, a hypermethylated sequence is a positive signal against an unmethylated background, making it more easily detectable than genetic alterations such as loss of heterozygosity, for which a negative signal must be recognized against a dominant positive background [27]. Methylation can be viewed as a result of ageing, environmental exposure and disease. A role for a field defect, as previously shown for loss of heterozygosity in the breast [17], has been proposed for aberrant methylation in colon and lung tumor development [18-20], suggesting that not only the malignant cells, but also the surrounding (apparently normal) tissue harbors tumorigenic potential. This indicates that methylation markers in mammary epithelium that is not derived from tumor can be predictive for malignancy present in the same breast, making an epigenetic approach very well suited for monitoring purposes in nipple fluid. Fackler et al. [21] previously showed that, compared to cytology, analyzing promoter methylation of a similar gene set using quantitative multiplex methylation-specific PCR in ductal lavage cells doubled the detection rate of breast cancer. From these data, one might conclude that DNA in nipple fluid represents epigenetic aberrations that predict the presence of tumor, irrespective of the amount of ducts or area of the breast that it is derived from. In a previous study we found that the methylation status of a panel of 11 tumor suppressor genes (RARB, RASSF1, TWIST1, CCND2, ESR1, SCGB3A1, BRCA1, BRCA2, CDKN2A, APC, CDH1) predicts sporadic as well as hereditary breast cancer with high accuracy ( 92 and $86 \%$, respectively), and can be very useful for early detection of cancer in nipple fluid of highrisk women (unpubl. data). Since the quantitative multiplex methylation-specific PCR method encompasses a nested multiplex PCR method, methylation values can be derived from very small amounts of DNA, making it especially suitable for detection in nipple (aspiration) fluid, where the amount of cellular material and/or free DNA is generally scarce [6].

Besides using an epigenetic approach, genomic and proteomic analysis in the same aspirates might soon become feasible and provide enormous opportunities for

diagnostic medicine. Until now, detection of chromosomal instability [22], microsatellite instability [23] and loss of heterozygosity turned out to be insufficiently predictive of breast cancer risk. Possibly, a genome-wide approach, performing mutation analysis of multiple genes that are often found mutated during breast carcinogenesis is more successful in discovering new genomic biomarkers in nipple fluid. Using time-of-flight mass spectrometry (SELDI-TOF) combined with sophisticated bioinformatics, proteomic patterns for large numbers of samples can be analyzed in a high-throughput fashion, requiring minimal amounts of material [24]. Recent studies show promising results $[25,26]$, identifying proteomic profiles that differentiate between normal breast tissue and breast cancer specimens. However, concerns about the reproducibility and reliability of the method have to date prevented the identification of a panel of proteomic markers in nipple aspirate fluid accurately predicting breast cancer.

\section{Conclusion}

Oxytocin-supported nipple aspiration provides a valuable tool for accessing mammary epithelium, providing sufficient material for a broad spectrum of genetic, epigenetic and proteomic analyses in the large majority of women. Monitoring molecular changes in nipple fluid can be regarded as a very interesting source of information on the genomic makeup of the breast, possibly contributing to more accurate breast cancer risk assessment in the near future.

References

Pathobiology 2008;75:149-152
1 Berry DA, Cronin KA, Plevritis SK, Fryback DG, Clarke L, Zelen M, Mandelblatt JS, Yakovlev AY, Habbema JD, Feuer EJ: Effect of screening and adjuvant therapy on mortality from breast cancer. N Engl J Med 2005;353: 1784-1792.

-2 Brekelmans CTM, Seynaeve C, Bartels CCM, Tilanus-Linthorst MMA, Meijers-Heijboer EJ, Crepin CMG, van Geel AN, Menke M, Verhoog LC, van den Ouweland A, Obdeijn IM, Klijn JGM: Effectiveness of breast cancer surveillance in BRCA1/2 gene mutation carriers and women with high familial risk. J Clin Oncol 2001;19:924-930.

3 Fabian CJ, Kimler BF, Mayo MS, Khan SA Breast-tissue sampling for risk assessment and prevention. Endocr Relat Cancer 2005; 12:185-213. 
4 Wrensch MR, Petrakis NL, Gruenke LD, Ernster VL, Miike R, King EB, Hauck WW: Factors associated with obtaining nipple aspirate fluid: analysis of 1,428 women and literature review. Breast Cancer Res Treat 1990; 15:39-51.

-5 Suijkerbuijk KP, van der Wall E, van Diest PJ: Oxytocin: bringing magic into nipple aspiration. Ann Oncol 2007;18:1743-1744.

-6 Dooley WC, Ljung BM, Veronesi U, Cazzaniga M, Elledge RM, O'Shaughnessy JA, Kuerer HM, Hung DT, Khan SA, Phillips RF, Ganz PA, Euhus DM, Esserman LJ, Haffty BG, King BL, Kelley MC, Anderson MM, Schmit PJ, Clark RR, Kass FC, Anderson BO, Troyan SL, Arias RD, Quiring JN, Love SM, Page DL, King EB: Ductal lavage for detection of cellular atypia in women at high risk for breast cancer. J Natl Cancer Inst 2001;93: 1624-1632.

7 Wrensch MR, Petrakis NL, Miike R, King EB, Chew K, Neuhaus J, Lee MM, Rhys M: Breast cancer risk in women with abnormal cytology in nipple aspirates of breast fluid. J Natl Cancer Inst 2001;93:1791-1798.

8 Mitchell G, Antill YC, Murray W, Kirk J, Salisbury E, Lindeman GJ, Di IJ, Milner AD, Devereaux L, Phillips KA: Nipple aspiration and ductal lavage in women with a germline BRCA1 or BRCA2 mutation. Breast Cancer Res 2005;7:R1122-R1131.

\$9 Petrakis NL: Physiologic, biochemical, and cytologic aspects of nipple aspirate fluid. Breast Cancer Res Treat 1986;8:7-19.

10 Fabian CJ, Kimler BF, Zalles CM, Klemp JR, Kamel S, Zeiger S, Mayo MS: Short-term breast cancer prediction by random periareolar fine-needle aspiration cytology and the Gail risk model. J Natl Cancer Inst 2000;92: 1217-1227.
Arun B, Valero V, Logan C, Broglio K, Rivera $E$, Brewster $A$, Yin $G$, Green M, Kuerer $\mathrm{H}$, Gong Y, Browne D, Hortobagyi GN, Sneige N: Comparison of ductal lavage and random periareolar fine needle aspiration as tissue acquisition methods in early breast cancer prevention trials. Clin Cancer Res 2007;13:4943-4948.

12 Johnson-Maddux A, Ashfaq R, Cler L, Naftalis E, Leitch AM, Hoover S, Euhus DM: Reproducibility of cytologic atypia in repeat nipple duct lavage. Cancer 2005; 103:11291136.

13 Suijkerbuijk KP, van der WE, van LT, Vooijs $M$, van Diest PJ: Epigenetic processes in malignant transformation: the role of DNA methylation in cancer development. Ned Tijdschr Geneeskd 2007;151:907-913.

14 Baylin SB, Herman JG: DNA hypermethylation in tumorigenesis: epigenetics joins genetics. Trends Genet 2000;16:168-174.

15 Ehrlich M: DNA methylation in cancer: too much, but also too little. Oncogene 2002;21: 5400-5413.

16 Esteller M: Aberrant DNA methylation as a cancer-inducing mechanism. Ann Rev Pharmacol Toxicol 2005;45:629-656.

17 Deng G, Lu Y, Zlotnikov G, Thor AD, Smith HS: Loss of heterozygosity in normal tissue adjacent to breast carcinomas. Science 1996; 274:2057-2059.

18 Issa JP, Ahuja N, Toyota M, Bronner MP, Brentnall TA: Accelerated age-related $\mathrm{CpG}$ island methylation in ulcerative colitis. Cancer Res 2001;61:3573-3577.

19 Shen L, Kondo Y, Rosner GL, Xiao L, Hernandez NS, Vilaythong J, Houlihan PS, Krouse RS, Prasad AR, Einspahr JG, Buckmeier J, Alberts DS, Hamilton SR, Issa JP: MGMT promoter methylation and field defect in sporadic colorectal cancer. J Natl Cancer Inst 2005;97:1330-1338.

20 Guo M, House MG, Hooker C, Han Y, Heath E, Gabrielson E, Yang SC, Baylin SB, Herman JG, Brock MV: Promoter hypermethylation of resected bronchial margins: a field defect of changes? Clin Cancer Res 2004;10: 5131-5136.
21 Fackler MJ, Malone K, Zhang Z, Schilling E, Garrett-Mayer E, Swift-Scanlan T, Lange J, Nayar R, Davidson NE, Khan SA, Sukumar S: Quantitative multiplex methylation-specific PCR analysis doubles detection of tumor cells in breast ductal fluid. Clin Cancer Res 2006;12:3306-3310.

22 King BL, Tsai SC, Gryga ME, D’Aquila TG, Seelig SA, Morrison LE, Jacobson KKB, Legator MS, Ward DC, Rimm DL, Phillips RF: Detection of chromosomal instability in paired breast surgery and ductal lavage specimens by interphase fluorescence in situ hybridization. Clin Cancer Res 2003;9:15091516.

23 Zhu W, Qin W, Ehya H, Lininger J, Sauter E: Microsatellite changes in nipple aspirate fluid and breast tissue from women with breast carcinoma or its precursors. Clin Cancer Res 2003;9:3029-3033.

24 Wulfkuhle JD, Liotta LA, Petricoin EF: Proteomic applications for the early detection of cancer. Nat Rev Cancer 2003;3:267-275.

-25 Pawlik TM, Fritsche H, Coombes KR, Xiao L, Krishnamurthy S, Hunt KK, Pusztai L, Chen JN, Clarke CH, Arun B, Hung MC, Kuerer HM: Significant differences in nipple aspirate fluid protein expression between healthy women and those with breast cancer demonstrated by time-of-flight mass spectrometry. Breast Cancer Res Treat 2005;89: 149-157.

26 Sauter ER, Shan S, Hewett JE, Speckman P, Du Bois GC: Proteomic analysis of nipple aspirate fluid using SELDI-TOF-MS. Int J Cancer 2005;114:791-796.

27 Herman JG, Baylin SB: Gene silencing in cancer in association with promoter hypermethylation. N Engl J Med 2003;349:20422054. 